\title{
Women as Social Enterpreneurship and Use of Technology
}

\author{
Prof. Dr. Fahriye Altınay ${ }^{1}$, Prof. Dr. Zehra Altınay ${ }^{2}$
}

\begin{abstract}
Transformation of societies relies on the use of technology. Changes and development require the reality of practicing the transformative learning theory. As transformative learning theory sheds a light on the perspective changes in life styles, women are considered key parties to be involved in the transformative learning process in order to experience social entrepreneurship. The use of technology is an opportunity for women to gain capacity in the social entrepreneurship within the digital societies. This research study aims to evaluate the small cases through the perceptions of women on the use of technology and social entrepreneurship. Qualitative research study was conducted that self report was used. Cases were considered from the experiences of women on social entrepreneurship and technology. In order to analyze data, thematic analysis was conducted. Research results revealed that women as separate cases have learned technology through use of social media. They are social entrepreneurs that they make projects for facilitating social responsibility to share knowledge, researching and learning new things. They underlined that technology foster their skills to continue their working performance and making projects in the society. As these experiences become transformation for their lives, women gain a chance to be employed and open their own works through the merits of technology.
\end{abstract}

Keywords: digitalization, learning, women, social entrepreneurship, technology, transformation

\section{Introduction}

Digitalization of information has changed the nature of learning. Transformative learning theory has become apparent in this process. As transformative learning theory highlights the changes on perspective systems, the use of technology and internet became medium of these changes( Lu and Churchil, 2014). This leads to share of resources, enhance motivation, and facilitate reflection, social interaction. Social projects become essential for the entrepreneurship in knowledge building. Entrepreneurship makes the spirit of teamwork, innovation. Social responsibility is a crucial factor to facilitate actions for the productivity.

Especially, adults experience construction of knowledge through transforming their experiences and beliefs in a new manner. Experimenting new roles through new frames of learning context and tools indicate that transformative learning theory can be used in practice (Humphrey, 2014;. Christine, Carey, Robertson, Grainger, 2015). Social entrepreneurship is a major example for this in order to make behavioral changes in the society. Social entrepreneurship made a reflection and become a mirror as a concrete example for the transformative learning. Technology becomes a bridge to concern how social entrepreneurship can be enriched.

| ${ }^{1}$ Nicosia, Near East University, Societal Research and Development Center, Educational Sciences Institute. ${ }^{2}$ Nicosia, Near East University, Societal Research and Development Center, Educational Sciences Institute, Computer Education and Instructional Technology Department. 
As technology becomes medium of activities, sharing and experiencing, construction of knowledge fosters different ways of learning at different contexts. Digitalization reshapes the nature of work, roles and life styles and different ways of reaching out knowledge is occurring. Values of works and efforts are enriched with the support of technology (Altinay,Dagli, Altinay, 2017). In this respect, project based activities become a result of behavioral changes to understand meaning of people's own experiences (Akcil, Altinay, Altinay, 2016;Madsen, Cook, 2010).

In this digital age, there is an intensified need to learn our experiences and beliefs, values rather than others' (Kim, Lin, , Qiu, 2015). As transformative learning relies on the result of life dilemma, disorienting dilemma, it is obvious that women can practice this learning due to restrictions and limitations of societal values (Fountain, 2000). Hence technology becomes a bridge for women to acquire transformative learning to get education, gain capacity to understand their experiences.

Northern part of Cyprus is a small society which has economical and political restrictions. This causes dilemmas and inconsistency in societal values and systems. Use of technology and internet are used newly and new changes can be captured in developing countries. These conditions lead citizens especially adults to experience new ways of learning through technology, to revamp education systems and their experiences.

Especially women has started to be visible in social transformation through the use of technology. Digitalization and the technology enable women become pioneers of their employment and increase their capacity to acquire rich skills in their life styles. In this respect, the practice of transformative learning theory has arisen in the life of women and it can be related to the use of technology.

As recent studies underline that women encounter barriers in technology and working sector (Harris, Kruck, Cushman \& Anderson, 2009; Orser, Riding \& Stanley, 2012; Kemp, 2013; Madsen, Cook, 2010; Hemson and Peek, 2017), transformative learning experience is required to develop strategies to prevent gender barriers. This research aims to evaluate meaning of technology for women through transformative learning experiences and social entrepreneurship.

Following questions are intended to be answered in this research study;

How do women define technology facilities for entrepreneurship?

What does transformative learning experience foster social entrepreneurship?

\section{Methodology}

This research study relies on qualitative nature. The qualitative research stands on meanings, patterns of realities on evaluating perceptions of women regarding the research. In this respect, the research covers investigating the perceptions of women in regarding the use of technology and transformation learning experience. This research stands on detailed meanings and values on the experiences of women which reveal the facilities of technology in being social entrepreneur.

Case study within the frame of qualitative nature of research was employed. Case study is the detailed investigation of the 'case' 'situation' to do exploration. Therefore, different cases was evaluated and conducted upon research questions. Different cases are 
considered to be explored regarding to the experiences of women on social entrepreneurship and technology. Each case and stories of the women within the entrepreneurship were explored to determine whether technology facilities can foster social interaction and development in being social entrepreneurship.

Further to this, self report was conducted with main specific two questions. This is like a story telling process which the questions aim to explore the stories and cases in order to find out the bridge between technology and social entrepreneurship. Upon the cultural historical activity theory, technology is the medium to enrich the social patterns and foster communication facilities within the learning experience in every step of life. Besides the communication facilities, technology is the power of sustainable development of economy for producing, sharing and networking. Women are becoming social power of the development within the society in developing countries who can shape economy, foster sustainability and increase social welfare through social projects.

15 working women as cases were enrolled this investigation in order to explore constructive efforts of women power in social entrepreneurship and welfare of society with the support of technology. The fist question covers how women define technology in the life. The second one includes how they define facilities of technology in their social projects. They have 5-10 working experiences in the use technology since 20102012. For the internal validity of the question forms, three professionals have looked at questions in order to maintain reliability, and some of the questions were taken away from the question list. Two professionals have looked at written data and they reported that coding and key words are understandable and open (Miles, Huberman, 1994).

In this research, purposive sampling path has been used and research group was chosen with the snowball exampling. The selection of the cases as 15 working women is upon their projects that are based on impact and diffusion of projects within the society. Chosen 15 working women are from different sectors with the ages between 25-45 those made social projects in the society as a social entrepreneur. They become volunteer to be part of cases therefore, there is no any conflict of interest and ethical procedure during the process. The following Table 1 shows the selection criteria of 15 working women as cases of the study.

Table 1. Criteria of being a case of investigation

\begin{tabular}{|l|l|}
\hline Selection criteria & Having social project in society \\
\hline 1 & Diffusion impact of project \\
\hline 2 & Award of the project \\
\hline 3 & $\begin{array}{l}5-10 \text { working experience of technology in } \\
\text { projects }\end{array}$ \\
\hline
\end{tabular}

\section{Findings}

Research questions become a stance for enlightening the use of technology and transformative learning experience of women. 15 cases reflected their experiences on the use of technology and social enterpreneurship through transformative learning. Upon the themes of the research questions following themes and the exploration were done. 


\section{Examples of Selected Cases for Social Enterpreneurship}

\section{Case 1: Woman who carries social projects about disability}

I have enrolled social enterpeneurship projects in every step of my life. I am also disabled citizen which limitations and obstacles make me more social enterpeneur to help others. I have done social projects by sign hands project. With my association, I have organised trainnings for sign language in the society. Dissemination of the all projects are done through social media.

\section{Case 2: Woman who carries social projects about ecologic factors}

I have done projects related to children and the disabled citizens. Besides the projects, I am volunteer citizen to help those people in every step of my life. Significantly, I have organised particular organisations to do help for the citizens in rural areas. We have done social projects for financial support to the families who have low income in rural areas. Further to this, we have done projects and trainings to prepare people for work life and city life from the rural places. According to the scientific projects, I have done ecologic projects. For the dissemination of projects, social media is the powerful technology platform but project group members used messaging to immediate communicate for all actions.

\section{Case 3: Woman who carries social projects through lions clubs}

I have been carried social projects during six years in raltion to my lions club activities. There are various projects which aims to develop welfare of the society and also support the development of the individuals. In various fields, such as health, education, proposed social projects were done with volunteer members of the our association. Significantly, collaboration was done through offical meetings with related ministeries. We are doing all our efforts through sponsorships. Those activities encourage society to delegate, share and help each others in order to complement power and energy. We mainly concentrate on education, health, environment, children, disability. We announce and disseminate our activities through facebook, twitter and instragm. Rarely, we are doing press meetings in order to encourage society for the social responsibility projects.

Case 4: Woman who carries social projects for children

I have been supported social projects for the children until to that time. Diffusion of building children parks in rural areas have the great impact in society for the pyhsical and pshological, social developments of new generation. Those attempts were done through official meetings with related associations, municipalities. Dissemination of the projects were done through newspapers, social media to increase the attention on participation and involvement of the society.

\section{Meaning of Technology}

Cases explained the maning of technolgy regarding to their experiences. Following table indicated their reflections and interpretations in relation to the technology. 
Table 2. Interpretations on Technology

\begin{tabular}{|l|l|l|}
\hline What technology means & Cases & Interpretations \\
\hline Mobile phones, computers & 15 & Tools to use \\
\hline Innovation and solution & 15 & For the life \\
\hline No meaning & 2 & Non sense \\
\hline New things & 7 & Sharing events and new things \\
\hline Facilitator & 15 & $\begin{array}{l}\text { Communicate with others and } \\
\text { learn different contexts. }\end{array}$ \\
\hline
\end{tabular}

Most of the cases reported that technology is mobile phones, computers which they think technology as tools. 5 of the cases reflected that technology is innovation and solution for the life sytles. 7 of the cases indicated that technology become a tool to reach out new things, sharing events. 2 of the cases indicated that technology has not any meaning to be used. Cases underlined that new age refers to using technology. Therefore, cases shows that they are using technology to follow up new age. In addition, they indicated that technology provides them to gain new skills and new trends in their works and family life. Technology becomes facilitator to communicate with others and experience to learn different contexts.

\section{Technology and Women}

Cases provided their reflections by considering the role of technology for the women. Following table 3 indicated these interpretations.

Table 3. Technology and Women

\begin{tabular}{|l|l|l|}
\hline Technology and Women & Cases & Interpretations \\
\hline Supportive & 15 & Life \\
\hline Tool & 15 & Communication and teamwork \\
\hline Knowledge & 15 & Working context \\
\hline Opportunity & 12 & Life standards quality \\
\hline
\end{tabular}

Most of the cases stated that technology is supportive for women life. It becomes a tool to facilitate communication and sharing for enhancing teamwork. Most cases showed that teamwork through the support technology make their life easier. Technology is crucial for women especially extending their knowledge in their work and enhancing their capacity in the digital society. 12 of the cases showed that technology is an oppurtunity to enrich their work life and life styles. Cases underlined that technology make their life and understanding more constructive and valuable. In addition, cases underlined that technology is used by women for researching, shopping and designning which these are contributors to their life styles with the support of technology.

\section{A Milestone to Experience Transformative Learning as Social Enterpreneurship}

Cases explored their experiences on their social and economical benefits that they gained through the support of technology. Cases explained their interpratations as a milestone in which they become a social enterpreneur in order to acquire transformative learning. 
Following table 4 indicated the picture of these experiences and showed their experiences.

Table 4. Transformative Learning and Social Enterpreneurship

\begin{tabular}{|l|l|l|}
\hline Technology and Women & Cases & Interpretations \\
\hline Changes and development & 15 & Life ad transformative learning \\
\hline Promotion and visibility & 8 & Working context \\
\hline Social media & 5 & Capacity and skills development \\
\hline Group work & 7 & Service quality \\
\hline
\end{tabular}

Most of the cases stated that technology become milestone for their life. As technology provides changes and development of research participants lives, transformative learning experiences have happened. 8 of the cases underlined that technology fosters promotion of their works' and increases the value and visibility of their works. 5 of the cases underlined that social media provide them to

increase the capacity and skills of designning, creativity in their works and reaching out others. 7 of the cases provide an insigt on the importance of group work through the technology and they establish services through the support of technology to their customers.

Most of the cases underlined that their life styles have been changed with the impact of technology. Cases reflected that they have learned new skills and they became more informed about new trends related with their works. They reflected that technology enhanced their professional knoweledge and motivate them to create new trends regarding their interests.

Most of the cases showed performances on social projects for the value added role of the society. In this respect, one of the cases has involved in children park project. In this project, social media was used to collaborate among stakeholders. In addition, on of the cases experienced a project about hospitals, environment and homeless children, blind people school, animals. In these projects, newspapers, facebook, twitter and instagram were used to facilitate promotion of activities.

One of the case conducted social enterpreneurship based projects for deaf people. Spoken Hands project becomes a social value for the society to make equality. Furthermore, making for unity and motivation, project about deaf children to make their rights, education services are conducted. Project about ecological factors was conducted by one of the cases, social media was used to deliver social responsibility.

\section{Conclusion and Discussion}

As the characteristics nature of a small society on the island has the characterictic of conflict and dilemmas due to economical and political problems, these conflicts make citizen to research more and more to adapt new changes and open the debates and restrictions in their productions. Technology become an oppurtunity to open new ways to overcome barriers and understand global world in order to adapt the new changes. In this respect, generations have started to learn technolgoy together and they have started into integrate technolgy to their life styles. This behaviour make 
citizens to experience transformative learning process through the support of technology.

Transformative learning plays a great role within the breaks of digitalization of societies in adapting new changes and create new life styles. In this respect,citizents in small island have been trying to adapt new technologies and new learning tools in order to capture the essence of social tranformation and unity. Because small island has conflicts and restrtictions unemployment has increased. Due to these reasons, digitalization and the technology is becoming a bridge to foster transformation and open a gate for employment for new generations. Technology can also be used for valuing leisure times and enjoyment in the lives of the people.

Social enterpreneurship is important to encapsulate the nature of teamwork and innovation. As transformative learning stands on critical reflection and questioning, adult learners have strated to use this process through the support of technology. With the use of technology, citizens become reflective practitioners in their works (Fetherston, Kelly, 2007).

It is obvious that women have experienced tranformative learning process through the use of technology. They increased their skills and capacity to be more employed. They use social media to diffuse information and share their experiences with the created online community.

In this research study, it can be seen that women engaged in dialectic discourses with the use of technology they experienced transformative learning. It can be seen that women gained professional identity in their works with the support of technology. They gained skills of team work and creativity.

As transformative learning relies on changing and adapting frames of references (Cranton, 2010), in this research study, it is revealed that women from different cases use the technology to transform their working conditions and enrich their working standards and social projects. They use social media to promote their works, social projects and they use technolgoy to research and design new things for their working conditions. In addition, they use technology to add a value for their leisure time. In further studies, it is essential to conduct services management for working conditions of women and improve economical investment capacity of women in the developing countries.

\section{References}

Akcil, U., Altinay, F., Altinay, Z. Assesing the Effects of Managers in the Digital Age on the Management Process of Digital Citizenship Roles. The Antropologist, 23(1/2). 2016.

Altinay, F., Dagli, G. and Altinay, Z., Role of technology and management in tolerance and reconciliation education. International Journal of Methodology, 15(3), 68-72. 2017

Christine, M.,Carey, M., Robertson, A., Grainger, P. Putting tranformative learning into practice. Australian Journal of Adult Learning, 55(1), 9-30. 2015

Cranton, P. Transformative learning in an online environment. International Journal of Adult Vocational Education and Technology, 1(2), 1-10. (2010). doi:10.4018/javet.2010040101

Fetherston, B., \& Kelly, R. Conflict resolution and transformative pedagogy: A gronde theory research project on learning in higher education. Journal of Transformative Education, 5(3), 262-285. 2007. doi:10.1177/1541344607308899 
Fountain, J. F. Constructing the information society: women, information technology, and design. Technology in society, 22 (1), 45-62. 2000. https://doi.org/10.1016/S0160-791X(99)00036-6

Gazi A., Z. \& Aksal A., F. Technology as mediation tool for improving teaching profession in higher education practices. EURASIA Journal of Mathematics Science and Technology Education, 13(3), 803-813. 2017. DOI 10.12973/eurasia.2017.00644a

Harris, N. S. E. Cushman K., P., Anderson, R. D. Technology Majors: Why are Women Absent? Journal of Computer Information Systems, 50( 2), 23-30. 2009

Hemson, D., Peek, N. Training and integrating rural women into technology: a study of Renewable Energy Technology in Bangladesh. Gender, Technology and Development, 21(1-2), 46-62. 2017. https://doi.org/10.1080/09718524.2017.1385315

Humphrey, K. R.Lessons Learned from Experiential Group Work Learning. Social Work With Groups, 37(1), 61-72. 2014.

Karasar, N. Bilimsel araştırma yöntemi. Ankara: Nobel Yayın Dağıtım. 2008.

Kemp, L. J. Progress in female education and employment in the United Arab Emirates towards Millennium Development Goal (3): gender equality". Foresight, 15(4), 264-277, 2013. https://doi.org/10.1108/FS-02-2012-0007

Kim , Y. H., Lin, P. M. C., Qiu, H. Experiential Learning: Being a Real-Event Planner. Journal of Teaching In Travel \& Tourism, 15(4), 382-401. 2015.

$\mathrm{Lu}, \mathrm{J}$., Churchill, D. The effect of social interaction on learning engagement in a social networking environment. Interactive Learning Environments, 22(4), 401-417. 2014.

Miles BM, Huberman AM. Qualitative Data Analysis: An expanded source book. 2nd ed. California, USA: Sage Publications; 1994.

Orser, B. Riding, A., Stanley, J. Perceived career challenges and response strategies of women in the advanced technology sector. Entrepreneurship \& Regional Development, 24(1-2),73-93. 2012

Susan R. Madsen, S. R., Cook, B. J. Transformative learning: UAE, women, and higher education. Journal of Global Responsibility, 1(1), 127-148. 2010 https://doi.org/10.1108/20412561011039744. 